\title{
Nocturnal digital surveillance in aged populations and its effects on health, welfare and social care provision: a systematic review
}

Matt X. Richardson ( $\nabla$ matt.richardson@mdh.se )

Mälardalen University

Maria Ehn

Mälardalen University

Sara Landerdahl Stridsberg

Mälardalen University

Ken Redekop

Mälardalen University

Sarah Wamala-Andersson

Mälardalen University

Research Article

Keywords: health and welfare technology, nocturnal surveillance, remote monitoring, aging, elderly

Posted Date: April 15th, 2021

DOI: https://doi.org/10.21203/rs.3.rs-373330/v1

License: (c) (1) This work is licensed under a Creative Commons Attribution 4.0 International License. Read Full License 


\section{Abstract}

\section{Background}

This systematic review summarized the effects of nocturnal digital surveillance technologies on health, welfare and social care provision outcomes in populations $\geq 50$ years, compared to standard care.

Primary studies published 2005-2020 that assessed these technologies were identified in 11 databases of peer-reviewed literature and numerous grey literature sources. Five publications out of 629 met inclusion criteria. The Risk of Bias 2.0 and ROBINS-I tools were used for quality assessment.

\section{Result}

Health-related outcomes (e.g. injuries, unexplained absences) and social care outcomes (e.g. staff burden) did not differ between interventions and standard care. Quality of life and affect showed improvement with some interventions, as did economic outcomes in one setting. The quality of studies was low however, with a serious to critical risk of bias.

\section{Conclusion}

We found little evidence for the benefit of nocturnal digital surveillance interventions as compared to standard care in several key outcomes. Higher quality intervention studies should be prioritized in future research to provide more reliable evidence.

\section{Background}

Nocturnal digital surveillance systems are health and welfare technology interventions used to monitor elderly, both with and without cognitive or physiological dysfunctions, in the home or institutional care settings. Such systems generally use sensors or cameras to determine if an individual is present at a specific location in the night, and upon deviation from a normal, "desired" status sends a message or alarm to an external, specified resource such as a formal or informal caregiver. In other cases, the surveillance system replaces an external resource that would have physically visited the individual during the night, often on a pre-determined schedule, to ensure they did not require assistance; the individual is instead observed digitally. The external resource following-up on or receiving messages regarding the individual can then assess if any action is required to ensure their safety and well-being.

The proposed advantages to such surveillance interventions are several. The disturbance created by physically visiting individuals during their sleep is conceivably reduced since a digital monitor can be remotely and silently activated. The constancy of the surveillance system is another, as adverse events may occur between intermittent physical visits and not be discovered until a significant period has elapsed. Users might feel an increased sense of security or reduced level of worry, allowing sleep quality to improve. Public services may expect downstream cost-savings due to reductions in resource-intensive operations, whereby employees must be visit individuals throughout the night. The costs for personnel, 
transport, and administration would conceivably decrease if distance-based surveillance could perform the same tasks. Furthermore, during the Covid-19 pandemic, the interest in and use of these systems has increased substantially in order to reduce physical contact with populations at greater risk of serious illness, while still maintaining a necessary standard of care.

Developments in Sweden provide an indication of the increasing usage of digital night surveillance. The number of municipalities that provide such technologies in individual residences has increased from 23 in 2016 to 66 in 2020, and for institutional residences from six to 44 over the same period. Of Sweden's 218 municipal elderly care services, $66 \%$ are currently using digital surveillance interventions in the home, as are $33 \%$ of public services responsible for care of the functionally disabled.(1) Institutional use is even more prevalent; $90 \%$ of elderly care institutions in Sweden use some form of digital nocturnal surveillance intervention, as do $80 \%$ of other types of group residences.(1) The estimated potential economic savings for nationally implementing digital night surveillance in elderly care is 1,4 billion SEK, or 140 SEK per individual.(2) The municipality of Gothenburg estimated that annual savings amounted to 71000 SEK per user after implementing such a system for elderly persons living at home, instead of nightly visits.(3)

Considering the increasing use of these interventions, the importance of assessing outcomes of interest is also increasing in order to determine the actual and potential benefits to individuals, their informal caregivers, and public services.

\section{Objective}

The question that this systematic review aimed to answer was: How does nocturnal digital surveillance affect health, welfare and social care provision in aged populations compared to standard care?

The specified population for the review was adults 50 years of age and older residing in the home or nonpenal care institutions, in OECD countries or those of an equivalent level of development. Interventions that could be included were digital cameras, sensors, alarms, or other place-based, non-physiological monitoring devices that were used specifically during the night. The intervention(s) were compared with standard care, typically no surveillance or on-site, person-based surveillance. Outcomes of interest were:

- Health-related outcomes, including rate of injury, unexplained absence, and other adverse medical outcomes

- Welfare outcomes, including quality of life, perceived safety or security, and other related welfare outcomes

- Social care provision outcomes including the welfare of, and burden on, families, informal caregivers and social care staff and organisations, as well as related economic outcomes for public services (e.g. transportation, search costs). 


\section{Methods}

\section{Protocol and registration}

\section{This systematic review was prospectively registered in the PROSPERO international prospective register of systematic reviews (reg CRD42020198438, September 11, 2020). This register (https://www.crd.york.ac.uk/prospero/) was searched for ongoing or previously published reviews with similar topics and criteria before registering our own review and initiating the search strategy; none were identified as overlapping.}

\section{Inclusion criteria}

The included study types were randomized control trials (RCTs) including randomized cross-over trials, cluster randomized trials, and within-subjects designs, as well as quasi-experimental studies including non-randomized control studies, before-and-after studies, and interrupted time series. Mixed-methods studies that included relevant quantitative data were included. Grey literature including reports from public agencies, theses, and conference abstracts with similar study designs as for the peer-reviewed literature were also included. Studies must have been published between January 2005 and August 2020, in English, French, or Scandinavian languages.

The included population was adults 50 years or older residing in the home or non-penal care institutions in OECD countries or countries of equivalent developmental level. Interventions must have been digital technologies, using audiovisual or sensor-based monitoring, specifically intended for nocturnal use.

\section{Exclusion criteria}

Proof-of-concept, conceptual, observational, and qualitative studies that e.g. described attitudes or feasibility without providing any relevant quantitative outcome data were excluded from the review. Systematic, literature and scoping reviews, as well as other grey literature not reporting primary study results were excluded.

Hospitalized populations were excluded. Interventions intended for continuous monitoring of specific physiological conditions (i.e. apnea, seizure, heart rate etc.) were not included, nor were interventions used for daytime surveillance or outside the home or institutional setting. 
Search strategy

\section{Peer-reviewed literature}

The following databases were searched between July and October 2020 for peer-reviewed literature: PubMed (pubmed.ncbi.nlm.nih.gov), Cinahl Plus (EBSCOhost), Cochrane Library (www.cochranelibrary.com), Web of Science (www.webofknowledge.com), IEEE Xplore (ieeexplore.ieee.org), APA Psycinfo (EBSCOhost), Academic Search Elite (EBSCOhost), Applied Social Sciences Index and Abstracts-ASSIA (ProQuest), International Bibliography of the Social Sciences - IBSS (ProQuest), Scopus (www.scopus.com), and Soclndex (EBSCOhost).

Grey literature

Searches in the grey literature were conducted in September 2020 in the following international registers and databases of grey literature: OpenGrey (www.opengrey.eu), OAlster (oaister.worldcat.org), Bielefeld Academic Search Engine - BASE (www.base-search.net), WHO ICTRP (apps.who.int/trialsearch), ClinicalTrials.gov (clinicaltrials.gov/ct2/home), the International Health Technology Assessment Database (https://www.inahta.org/hta-database), DART-Europe (www.dart-europe.eu/basic-search.php), and Dissertations and Theses A\&l (ProQuest). National sources of grey literature in the Nordic countries including publications and websites of public agencies, national databases, NGOs and interest groups were also searched in October 2020 using search strings in the respective Scandinavian languages. A complete list of the grey literature sources searched with links to websites is included in Supplement 1.

Searches in both types of information sources were followed up with searches in Google Scholar in English, 


\section{Swedish, Norwegian, Danish, and Finnish languages.}

\section{Search strings}

\section{Peer-reviewed literature}

The following search string was used in searches of the peer-reviewed literature databases:

(elderly OR "older adult*" OR "older person*" OR aged (MeSH only databases)) AND (nocturnal OR "nighttime" OR "nighttime" OR "night time") AND (surveillance OR camera* OR "video monitor*" OR "in-home monitor*" OR "home monitor*" OR "safety monitor*" OR "digital monitor*" OR telemonitor* OR "remote monitor*" OR "digital camera" OR "digital sensor*" OR "monitoring system*")

The search string was adjusted in those databases that imposed limitations on search fields, operators and/or wildcards, so that several overlapping searches may have been required.

\section{Grey literature}

If the database allowed, the search string was identical to that used in the peer-reviewed literature searches. However, many databases did not allow advanced search strings, in particular websites of e.g. public agencies. The search string from the peer-reviewed literature was therefore divided into its components (delineated by the AND operator in that search string), or if necessary, into individual keywords. Screening of clearly irrelevant literature in these cases was conducted during the search.

An example of this was a grey literature database with a search maximum of 5 terms and without phrase searching. The resulting publications at each step in the search strategy were then opened, and the search terms re-combined in-document to determine inclusion in the study selection process:

Grey literature database search (maximum 5 terms), with results downloaded after each step

Search 1: elderly OR older adult OR older person OR aged

Search 2: nocturnal OR night-time OR nighttime OR night

Search 3: surveillance OR camera OR video monitor OR in-home monitor OR home monitor

Search 4: safety monitor OR digital monitor OR telemonitor OR remote monitor OR digital camera

Search 5: digital sensor OR monitoring system

Presence of any of terms in 1 AND any terms in 2 AND any terms in ( 3 or 4 or 5 ) in a publication: included in study selection process. 


\section{Study selection process}

Altogether, 629 publications were identified in the literature search after removal of duplicates. All identified publications were entered into the Covidence systematic review software (Veritas Health Innovation Ltd, Melbourne, Australia, www.covidence.org) for the remainder of the review process. The PRISMA guidelines for reporting of systematic reviews(4) were followed and a summary of the study selection results can be found in Table 1 .

Two researchers and one information sciences specialist (hereafter referred to as reviewers) conducted the review process, which had four steps:

Initial screening: The titles, keywords, and in some cases abstracts of the 629 publications were screened for relevance by two reviewers independently. Each reviewer voted on whether the publication was relevant for further review; consensus resulted in inclusion or exclusion at this step. Any remaining conflicts were resolved by the third reviewer.

Full-text screening: The full text for all publications proceeding to this step were obtained and read independently by two reviewers. Each reviewer voted on whether the publication was relevant for inclusion in the review and to proceed to data extraction. Consensus resulted in inclusion or exclusion at this step, and any conflicts remaining were resolved by the third reviewer.

Citation searching: We searched the cited references of seven review-type publications that proceeded past the screening stage but were then excluded as they were not original studies. We also searched Scopus for articles citing the same seven review-type publications. The cited references for, and citations of, any publications included after the full-text screening step were also searched in the same manner. These citation searches were conducted in August and September 2020. Both the cited and the citing articles followed the steps preceding this one in the review process.

Data extraction: Essential information regarding the study aim, design, conduct, population, intervention, and outcomes, as well as results data for relevant outcomes, was extracted from the publication by two reviewers independently. The template for this extraction can be found in Supplement 2. Consensus resulted in inclusion of the extracted data in the review's summary of findings. Conflicts in extraction were discussed among the two reviewers, and any remaining conflicts remaining were resolved by the third reviewer.

Risk of bias assessment: The included individual publications were assessed for risk of bias at the study level by two researchers independently. The criteria assessed for randomized studies followed the Risk-ofbias tool 2.0(5) and included the method for random sequence generation, allocation concealment, blinding of participants and personnel, blinding of outcome assessment, the completeness of outcome data, the possibility of selective outcome reporting, and other sources of bias. For non-randomized studies, the ROBINS-I tool(6) was used to assess bias due to confounding, missing data and selective reporting, and in selection of participants, classification of and deviations from interventions. Consensus 
about the risk of bias resulted in inclusion of the risk assessment in the review's summary of findings. Conflicts in risk assessment were discussed among the two reviewers, and any conflicts remaining were resolved by the third reviewer.

\section{Summary measures}

\section{The principle study measure was difference in means. In those cases where means were not the primary statistic in the study (e.g. cost- benefit analyses), the main statistic in the study was reported.}

\section{Results}

\section{Study selection}

Table 1. PRISMA flowchart for selection of publications. 


\begin{tabular}{|c|c|c|}
\hline $\begin{array}{l}648 \text { publication } \\
\text { references were } \\
\text { imported for } \\
\text { screening }\end{array}$ & $\rightarrow$ & $\begin{array}{l}19 \text { duplicates were removed. } 596 \text { publications were found in the peer- } \\
\text { reviewed literature databases. } 3 \text { publications were found in Nordic grey } \\
\text { literature databases. The remainder were included at the citation } \\
\text { searching step and were found in the peer-reviewed literature. }\end{array}$ \\
\hline \multicolumn{3}{|l|}{$\downarrow$} \\
\hline $\begin{array}{l}629 \text { publication } \\
\text { references were } \\
\text { screened against } \\
\text { title, keywords and } \\
\text { abstract }\end{array}$ & $\rightarrow$ & 555 irrelevant publication references were excluded \\
\hline \multicolumn{3}{|l|}{$\downarrow$} \\
\hline \multirow{4}{*}{$\begin{array}{l}74 \text { full-text } \\
\text { publications were } \\
\text { assessed for } \\
\text { eligibility }\end{array}$} & \multirow[t]{8}{*}{$\rightarrow$} & 69 irrelevant publications were excluded for the following reasons: \\
\hline & & - 25 did not meet criteria for study design \\
\hline & & - 19 were not an original study (i. e. review/study protocol) \\
\hline & & - 10 did not meet criteria for outcomes \\
\hline \multirow{4}{*}{$\downarrow$} & & - 9 did not meet criteria for intervention types \\
\hline & & $\begin{array}{l}\text { - } 4 \text { did not meet criteria for population (or specific data for participants } \\
50 \text { years and older could not be extracted) }\end{array}$ \\
\hline & & - 1 was outside of dates allowed \\
\hline & & - 1 full text (conference abstract) could not be found \\
\hline
\end{tabular}

\section{Study characteristics}

The five included studies consisted of three peer-reviewed publications; of these, two were randomised controlled trials, and one was a variant of a cluster randomized trial (described by the study's authors as "quasi-experimental"). The final two publications were found in the grey literature and had nonrandomized, mixed methods designs. A summary of the study characteristics is presented in Table 2. 


\begin{tabular}{|c|c|c|c|c|}
\hline Author, year, region and title & Intervention & $\begin{array}{l}\text { Number of } \\
\text { participants }\end{array}$ & Design & $\begin{array}{l}\text { Duration of } \\
\text { intervention } \\
\text { follow-up }\end{array}$ \\
\hline $\begin{array}{l}\text { Holmes, D et al., 2007, USA, } \\
\text { "An evaluation of a monitoring } \\
\text { system intervention: falls, } \\
\text { injuries and affect in nursing } \\
\text { homes"(7) }\end{array}$ & $\begin{array}{l}\text { Bed exit sensor and } \\
\text { bathroom/bedroom } \\
\text { exit monitors }\end{array}$ & $\begin{array}{l}92 \text { care } \\
\text { institution } \\
\text { residents }\end{array}$ & $\begin{array}{l}\text { Variant of } \\
\text { cluster } \\
\text { randomized } \\
\text { trial }\end{array}$ & 15 months \\
\hline $\begin{array}{l}\text { Rowe, M et al., 2010, USA, } \\
\text { "Sleep in dementia caregivers } \\
\text { and the effects of a nighttime } \\
\text { monitoring system" (8) }\end{array}$ & $\begin{array}{l}\text { Bed occupancy } \\
\text { sensor and room } \\
\text { movement detector, } \\
\text { emergency door } \\
\text { alarm }\end{array}$ & $\begin{array}{l}53 \text { persons } \\
\text { with } \\
\text { dementia } \\
\text { and their } \\
\text { informal } \\
\text { caregivers }\end{array}$ & $\begin{array}{l}\text { Randomized } \\
\text { controlled } \\
\text { trial }\end{array}$ & 12 months \\
\hline $\begin{array}{l}\text { Rowe, M et al., 2009, USA, } \\
\text { "Reducing dangerous } \\
\text { nighttime events in persons } \\
\text { with dementia using a } \\
\text { nighttime monitoring } \\
\text { system"(9) }\end{array}$ & $\begin{array}{l}\text { Bed occupancy } \\
\text { sensor and room } \\
\text { movement detector, } \\
\text { emergency door } \\
\text { alarm }\end{array}$ & $\begin{array}{l}53 \text { persons } \\
\text { with } \\
\text { dementia } \\
\text { and their } \\
\text { informal } \\
\text { caregivers }\end{array}$ & $\begin{array}{l}\text { Randomized } \\
\text { controlled } \\
\text { trial }\end{array}$ & 12 months \\
\hline $\begin{array}{l}\text { Sivertsen and Lee, } 2019, \\
\text { Norway, "Digitalt nattilsyn og } \\
\text { søvnkartlegging: evaluering av } \\
\text { digital nattilsyn på REKO } \\
\text { Kastvollen” (Digital night } \\
\text { surveillance and sleep } \\
\text { mapping: evaluation of digital } \\
\text { night surveillance at REKO } \\
\text { Kastvollen)(10) }\end{array}$ & $\begin{array}{l}\text { Bed supervision } \\
\text { system }\end{array}$ & $\begin{array}{l}20 \text { care } \\
\text { institution } \\
\text { employees }\end{array}$ & $\begin{array}{l}\text { Mixed } \\
\text { methods }\end{array}$ & 9 months \\
\hline $\begin{array}{l}\text { Røhne et al., 2016, Norway, } \\
\text { "Effekt av Trygghetspakker: } \\
\text { erfaringar fra } \\
\text { velferdsteknologiprosjektet i } \\
\text { Lister regionen" (Effect of } \\
\text { security packages: experiences } \\
\text { from the welfare technology } \\
\text { project in Lister region)(11) }\end{array}$ & $\begin{array}{l}\text { Bed, safety and } \\
\text { door alarms }\end{array}$ & $\begin{array}{l}9 \text { persons } \\
\text { living at } \\
\text { home and } \\
\text { their } \\
\text { caregiving } \\
\text { public } \\
\text { employees }\end{array}$ & $\begin{array}{l}\text { Mixed } \\
\text { methods }\end{array}$ & 9 months \\
\hline
\end{tabular}

aHolmes et al. (2007) was found in PubMed Academic Search Elite, Cinahl, Cochrane (Trials), ASSIA, and Scopus; Rowe et al. (2010) in PubMed, Academic Search Elite, Cinahl, APA Psyclnfo, Cochrane (Trials), Web of Science, ASSIA, and Scopus; Rowe et al. (2009) in PubMed, Academic Search Elite, Cochrane (Trials), Web of Science, ASSIA, and Scopus; and Siwertsen and Lee (2019) and Røhne et al. (2016) in Nordic grey literature databases.

\section{Risk of bias assessment within studies}

Summaries of the assessed risk of bias for individual randomised and non-randomised studies are presented in Tables $3 a$ and $3 b$, respectively. 
Table 3a. Risk of bias assessments for individual randomized studies according to standardized criteria (Risk of Bias 2.0 tool(5)). A minus sign (-) indicates a high risk of bias assessment, and a plus sign (+) indicates a low risk of bias assessment for the randomized studies. A question mark (?) indicates some concerns of bias due to insufficient documentation or information. No symbol indicates the type of bias could not be assessed.

\begin{tabular}{|c|c|c|c|}
\hline $\begin{array}{l}\text { Randomized } \\
\text { studies } \\
\text { (RoB tool } 2.0 \\
\text { assessment } \\
\text { criteria) }\end{array}$ & $\begin{array}{l}\text { Holmes et al., } \\
2007(7)\end{array}$ & Rowe et al., 2010(8) & Rowe et al., 2009(9) \\
\hline $\begin{array}{l}\text { Random } \\
\text { sequence } \\
\text { generation }\end{array}$ & - & b & -c \\
\hline $\begin{array}{l}\text { Allocation } \\
\text { concealment }\end{array}$ & - & - & - \\
\hline $\begin{array}{l}\text { Blinding of } \\
\text { participants } \\
\text { / personnel }\end{array}$ & - & - & - \\
\hline $\begin{array}{l}\text { Blinding of } \\
\text { outcome } \\
\text { assessment }\end{array}$ & - & - & - \\
\hline $\begin{array}{l}\text { Incomplete } \\
\text { outcome } \\
\text { data }\end{array}$ & - & - & + \\
\hline $\begin{array}{l}\text { Selective } \\
\text { reporting }\end{array}$ & + & & \\
\hline Other bias & $?^{\mathrm{a}}$ & & \\
\hline Comments & $\begin{array}{l}\text { a staff showed } \\
\text { "resistance" to the } \\
\text { intervention and } \\
\text { altering methods of } \\
\text { care }\end{array}$ & $\begin{array}{l}\text { b } 8 \text { participants were } \\
\text { exempted from } \\
\text { randomization according to } \\
\text { preference or previous study } \\
\text { participation }\end{array}$ & $\begin{array}{l}\text { c } 8 \text { participants were } \\
\text { exempted from } \\
\text { randomization according to } \\
\text { preference or previous study } \\
\text { participation }\end{array}$ \\
\hline
\end{tabular}

Table 3b. Overall risk of bias assessments for individual non-randomized studies according to standardized criteria (ROBINS-I(6)), using the tools' ascending scale of risk (low, moderate, serious, critical, or No Information (NI), meaning the risk of bias could not be assessed). 


\begin{tabular}{|lll|}
\hline $\begin{array}{l}\text { Non-randomized studies } \\
\text { (ROBINS-I assessment criteria) }\end{array}$ & Sivertsen and Lee, 2019(10) & Røhne et al., 2016(11) \\
\hline Bias due to confounding & Critical & Serious \\
\hline Bias in selection of participants & $\mathrm{NI}$ & $\mathrm{NI}$ \\
\hline Bias in classification of interventions & Moderate & Serious \\
\hline Bias in deviations from intervention & Low & Low \\
\hline Bias due to missing data & $\mathrm{NI}$ & Critical \\
\hline Bias in measurement of outcomes & Serious & Serious \\
\hline Bias in selective reporting & Moderate & Moderate \\
\hline Overall Bias & Critical & Critical \\
\hline Comments/direction of bias & Unpredictable & Unpredictable \\
\hline
\end{tabular}

\section{Summary of findings}

The summary of findings for outcomes of the included studies is presented in Table 4.

Table 4. Summary of findings for outcomes of interest in the systematic review, with overall risk of bias assessment. 


\section{Nocturnal digital surveillance}

Population: Persons $\geq 50$ years of age

Settings: living at home or in care settings in OECD countries or equivalent

Intervention: digital sensors or monitors used at night for non-physiological surveillance

Comparison: Care as usual

\begin{tabular}{|c|c|c|c|}
\hline Outcomes & Relative change & $\begin{array}{l}\text { Number } \\
\text { of } \\
\text { studies }\end{array}$ & $\begin{array}{l}\text { Overall } \\
\text { risk of } \\
\text { bias }^{a}\end{array}$ \\
\hline
\end{tabular}

Health-related outcomes: injury, unexplained absence, other adverse medical outcome for receivers of care
1: No difference in rates of 2 injury $(0.02, p=0.828)$;

2: No difference in reduction of dangerous events $\left(X^{2}=1.72 ; p=0.79\right.$ for whole period; $X^{2}=3.58$; $p=0.058$ for when system turned on)
Welfare outcomes: $\quad 1$ : Improved affect $(-0.29$, $\mathrm{p}=0.34$ );

quality of life, perceived safety or security, and other related welfare outcomes for receivers of care

\section{Social care provision} outcomes:

burden informal caregivers and social care staff and organisations
2: $95 \%$ reported some improvement in quality of life
2,3: No difference in caregiver worry or sleep time/quality;
High 192 events and 9 events in the two respective studies.
2

High

High Improved affect (in 1 study) was directly predicted by increased direct care due to increased surveillance. Perceived QoL was reported by caregivers for patients in second study.

1: No difference in staff $4 \quad$ High
burden;

4: $75 \%$ reported improvement in work effectiveness and processes
3 studies reported no difference; 1 study reported improvement in work effectiveness and processes
Social care economic outcomes:

e.g. costs for visiting and transportation, search costs when missing.

$15 \%$ reduction in social $1 \quad$ High
care costs

Cost reduction
associated with fewer
required visits and
transportation. Avoided
costs due to ability to
remain in the home
instead of care
institutions not
assessed.

Cost reduction associated with fewer required visits and transportation. Avoided remain in the home institutions not

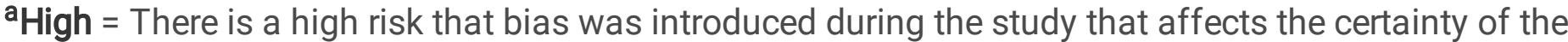
outcome and lowers confidence in the result. This assessment is equivalent to "High" for the Risk of 
Bias 2.0 tool, or Serious/Critical in the ROBINS-I tool.

Low $=$ There is a low risk that bias introduced during the study will affects the certainty of the outcome and lowers confidence in the result. This assessment is equivalent to "Low" for the Risk of Bias 2.0 tool, or Low/Moderate in the ROBINS-I tool.

\section{Risk of bias across studies}

Publication bias or other types of bias that may have affected the cumulative evidence were not systematically assessed in this review.

\section{Discussion}

\section{Summary of evidence}

This review aimed to determine if nocturnal digital surveillance affects health-related, welfare and social care provision outcomes in aged populations compared to standard care. The included studies suggest there is currently little evidence that a reduction in adverse health-related outcomes of care receivers can be achieved by using digital surveillance at night. Furthermore, the burden on informal caregivers and formal care staff does not appear to be reduced by using digital night surveillance, although work processes may be more effective in some cases. However, there is some evidence for improvement in quality of life for care receivers, and in their affect or emotional state, although the latter in one study was associated with a more direct level of care associated with increased surveillance. Cost reductions for formal social care services also appears possible, by reducing the number of required visits and transportation at night.

The quality of all included studies was low, however, which greatly affects the certainty of the outcomes and results. Several studies included in the current review failed to measure or assess potentially confounding factors such as age distribution, presence of illness or dementia in non-homogenous groups, the pre-assessed need for institutional care, availability of informal caregivers, and the geographic location of the user in relation to formal and informal care providers. The grey literature also yielded a substantial number of intervention assessments, however, their lack of rigorous effect evaluation excluded them from final compilation despite the current review's broader inclusion criteria. That is, most of the grey literature studies lacked formal study designs or approaches that involved manipulation or comparison of variables.

The lack of high-quality peer-reviewed literature that specifically assessed concrete outcomes of digital night surveillance methods is surprising, considering the widespread use of and reliance upon these interventions. The methods required to evaluate the effects of such interventions are straightforward and can follow established study designs with low risk of bias without difficulty, which makes their absence in the literature perplexing. Indeed, an earlier literature review of all types of monitoring technologies and their outcomes in independently living elderly people(12) supports this conclusion. In that review, the 
authors stated that research was widespread, but out of 141 included studies, only four provided longitudinal data and only one was a RCT. Most research focused on the accuracy, sensitivity and specificity of monitoring systems, failing to evaluate health-related effects of the end-users.

There are several possible explanations for the lack of high-quality literature assessing digital nocturnal surveillance. During the literature searches, several studies and reports could not be included in the review as they assessed multiple interventions, typically in the form of "safety packages", in a manner that did not allow assessment or reporting of the effects of individual components. Some of these studies included a form of nocturnal monitoring, but any effects may have been due to other daytime monitoring systems or active assistance interventions. Without the ability to identify which components have a positive effect on individuals receiving care, there is potential loss of health benefits and an increased risk of unnecessary expenses for care providers and public services.

The literature searches conducted identified many studies that were not eligible for inclusion in this review. Proof-of-concept studies of prospective nocturnal monitoring systems were abundant, suggesting that there is a considerable interest in further introducing similar interventions to the health and welfare sector. There was also a plethora of qualitative studies assessing the acceptance and feasibility of market-ready digital monitoring systems, suggesting that there was imminent intention to introduce such interventions. Finally, there were several studies specifically assessing the implementation processes involving monitoring technologies, suggesting that many interventions were indeed being used in society. That the number of these studies appeared to greatly outweigh studies of effects of the interventions in question is a fascinating result of this current review.

The lack of effect evaluation research of nocturnal digital monitoring might be explained if such interventions are simply viewed as a lower-cost alternative to current monitoring methods, namely physical visits by employees and the associated time and or transportation costs. While one article in the current review states that this is (likely) the case, adverse events were not reported as an outcome - and these are likely the costliest aspects associated with, and hopefully prevented by, any kind of monitoring. That article $(11)$ and three others $(7,8,10)$ in the review, did not find that employee burden decreased, either. While costs of initial purchase, implementation, training and establishment of centralized functions were not explicitly assessed in any of the articles, if a digital monitoring system does not result in a more favorable ratio between monitoring accuracy and work burden, then the prospective cost savings of a less person-intensive system run the risk of being negated by the increased need to deal with adverse events. Without established evidence to support implementation, care-providing organizations may, in contrast to their intentions, fail to achieve greater work efficiency and economic gain.

Health and welfare technologies are "technology-based interventions that aim at maintaining or promoting health, wellbeing, quality of life and/or increasing efficiency in the service delivery system of welfare, social and health care services, while improving working conditions of the staff".(13) While these types of interventions are not new, current evidence assessment frameworks for other types of clinical interventions are often not applied, or in other cases not fit-for-purpose to a degree that allows 
meaningful assessment. The UK-based National Institute for Health and Care Excellence (NICE) has however developed one such framework for Digital Health Technologies, in which interventions are classified by their intended functions and then associated with "tiers" of required evidence.(14) The authors of this survey followed the guidelines provided by NICE in order to categorize the nocturnal digital surveillance interventions in this review, and judged them as tier 3b, "active monitoring". Such technologies "automatically record information and transmit the data to a professional, carer or thirdparty organization, without any input from the user, to inform clinical management decisions", and examples such as sensors in the home are given. For this tier, NICE recommends high-quality intervention studies as a minimum evidence standard, and high-quality randomized controlled studies with validated condition-specific outcome measures in a locally relevant setting as a best practice evidence standard. The result of this current review shows that this higher standard of evidence for nocturnal digital surveillance interventions is not currently obtainable from the broader literature.

\section{Implications for policy and practice}

The results of this review suggest the need for greater explicitness in identifying outcomes of greatest importance to stakeholders prior to implementing a health and welfare technology intervention. This would facilitate assessment of both intended outcomes and unintended consequences and clarify evidence requirements in decision-making processes. While these interventions may be more heavily relied upon during the COVID-19 pandemic in order to reduce the risk of disease transmission, their effectiveness likely needs to be re-assessed when "normal" usage situations are once again established.

\section{Limitations}

This systematic review excluded daytime digital monitoring interventions. Several studies excluded from review may have assessed interventions that could be applicable both day and night, as data was not extractable for solely nocturnal assessment. The time-to-response outcome for adverse events, which may mediate health- and welfare-related outcomes, was also not assessed in this review. Searches were also restricted to Nordic languages in addition to English.

\section{Conclusions}

In summary, there is little evidence to show that nocturnal digital monitoring methods are superior to standard care in several relevant outcomes for stakeholders and end-users. If the main motivation to use digital monitoring is to reduce costs of care services, then the monitoring system would need to be as least as effective as standard care, but evidence of this is lacking due to a small number of high-quality assessment and evaluation studies.

\section{Declarations}




\section{Ethics approval and consent to participate}

This research is a systematic review of other previously published studies and did not require ethics committee approval as no participants were involved nor was participant data managed in any way.

\section{Consent for publication}

Not applicable.

Availability of data and materials

The datasets used and/or analysed during the current study are available from the corresponding author on reasonable request.

\section{Competing interests}

The authors declare that they have no competing interests.

\section{Funding}

The funding for this systematic review comes from Mälardalen University's general research funding, and the Sörmlandskontraktet regional financing partnership with the university. These funding sources contribute to the general conduct of research at Mälardalen University.

\section{Author's contributions}

Matt Richardson, Maria Ehn, and Sara Landerdahl-Stridsberg have conducted the literature searches in the review, assessed the obtained publications for inclusion, extracted data from these and conducted quality assessment of the included articles. These three authors have also verified the underlying data in the review. Matt Richardson, Sarah Wamala-Andersson, and Ken Redekop have established the study design and its approach, inclusion- and exclusion criteria, interpreted the data and written the article. All authors have reviewed the manuscript and left comments and suggestions for improvement.

\section{Acknowledgements}

Not applicable.

\section{Abbreviations}

NICE: National Institute for Health and Care Excellence, England

RCT: Randomized Controlled Trial

\section{References}


1. Socialstyrelsen. E-hälsa och välfärdsteknik i kommunerna 2020. Stockholm; 2020 May 2020. Report No.: 2020-5-6779.

2. Sveriges kommuner och regioner. Ekonomirapporten, October 2020. Stockholm; 2020.

3. Löfström C, Larsson N. Nattfrid? Om tillsyn på natten för äldre personer med hemtjänst. Hjälpmedelsinstitutet; 2012. Report No.: 12378.

4. Moher D, Liberati A, Tetzlaff J, Altman DG. Preferred reporting items for systematic reviews and meta-analyses: the PRISMA statement. BMJ. 2009;339:b2535.

5. Sterne JAC, Savović J, Page MJ, Elbers RG, Blencowe NS, Boutron I, et al. RoB 2: a revised tool for assessing risk of bias in randomised trials. BMJ. 2019;366:14898.

6. Sterne JA, Hernán MA, Reeves BC, Savović J, Berkman ND, Viswanathan M, et al. ROBINS-I: a tool for assessing risk of bias in non-randomised studies of interventions. BMJ. 2016;355:i4919.

7. Holmes D, Teresi JA, Ramirez M, Ellis J, Eimicke J, Kong J, et al. An Evaluation of a Monitoring System Intervention:Falls, Injuries, and Affect in Nursing Homes. Clinical Nursing Research. 2007;16(4):317-35.

8. Rowe MA, Kairalla JA, McCrae CS. Sleep in Dementia Caregivers and the Effect of a Nighttime Monitoring System. Journal of Nursing Scholarship. 2010;42(3):338-47.

9. Rowe MA, Kelly A, Horne C, Lane S, Campbell J, Lehman B, et al. Reducing dangerous nighttime events in persons with dementia by using a nighttime monitoring system. Alzheimer's \& Dementia. 2009;5(5):419-26.

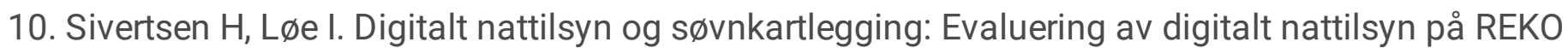
Kastvollen. Steinkjer: Trøndelag Forskning og Utvikling; 2019. Contract No.: TFoU-arbeidsnotat 2019:210.

11. Røhne M, Svagård I, Holmesland M. EFFEKT AV TRYGGHETSPAKKER: Erfaringer fra velferdsteknologiprosjektet i Lister regionen. Oslo: SINTEF IKT, omsorgsteknologi SIH-o; 2016 201612-12. Report No.: SINTEF A27917.

12. Peetoom KK, Lexis MA, Joore M, Dirksen CD, De Witte LP. Literature review on monitoring technologies and their outcomes in independently living elderly people. Disabil Rehabil Assist Technol. 2015;10(4):271-94.

13. Wamala S. International Health and Welfare Technology webinar series: Mälardalen University institutional website; 2020 [Available from: https://www.mdh.se/en/malardalenuniversity/research/health-and-welfare-/hwt-research-webinar-series.

14. NICE. Evidence Standards Framework for Digital Health Technologies. National Institute for Health and Clinical Excellence (NICE); 2019.

\section{Supplementary Files}

This is a list of supplementary files associated with this preprint. Click to download. 
- Supplements1and2.docx

- Supplements1and2.docx 